EDITORIAL

\title{
XIV International SOBRADPEC Congress and Translational Research Forum \\ Effective and interconnected participation of undergraduates and postgraduates in scientific investigation
}

\author{
Marina Rodrigues Garcia da Silveira \\ Undergraduate Medical student, scholarship from FAPESP and Monitor of the Digestive Surgery Division, Department of Surgery and Anatomy, \\ Ribeirao Preto Medical School, University of Sao Paulo, Ribeirao Preto-SP, Brazil.
}

\section{Orlando de Castro e Silva}

Full Professor and Head, Department of Surgery and Anatomy, Ribeirao Preto Medical School, University of Sao Paulo, Ribeirao Preto-SP, Brazil.

DOI: http://dx.doi.org/10.1590/S0102-86502014001300000

In the editorial of supplement number 1 of this trilogy we commented about the characteristics of the XIV International SOBRADPEC Congress and Translational Research Forum and regarding the approach to translational surgery and its insertion in current medical education as a generator of medical knowledge, as well as its importance in the teaching and learning process for both students and professors of medicine. In the present editorial, we shall now present some considerations regarding the profile of the authors of full papers published in these supplements of the XIV International SOBRADPEC Congress and Translational Research Forum chaired by Prof. Dr. Lydia Masako Ferreira, full professor of Escola Paulista de Medicina-UNIFESP. Thirtyeight full papers submitted by the authors were selected for this congress for publication in the three supplements of Acta Cirúrgica Brasileira, as well as 150 abstracts to be presented during the Event as posters or as oral presentations and to be published in the annals of the congress.

As shown in Figure 1, an initial analysis of the 38 original full papers selected for the supplements shows that $51 \%$ of the authors are professors of medicine, $21 \%$ are postgraduate students, $12 \%$ are undergraduate students, and only $2 \%$ are medical residents. The participation of undergraduates in scientific investigations is striking and leads us to reflect about the real interest of students in starting to work in research in a professional manner under the guidance of a professor of medicine as an adviser. Most of these students actively participated in the composition of the articles from data collection to the final writing, a fact that fully justifies their authorship or co-authorship, with merit. In addition, integration was observed between undergraduate and postgraduate students, as demonstrated by the distribution of the authors of the articles (Figure 1).

\section{Participation in Full Papers}

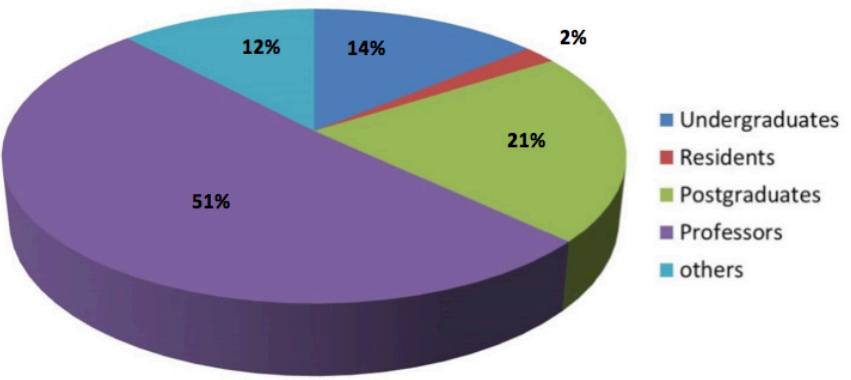

FIGURE 1 - Percent participation of undergraduates, residents, postgraduates and other professionals in full papers published in the Supplement trilogy of Acta Cirurgica Brasileira.

Regarding sex distribution, it can be seen that there was a clear prevalence of females among the undergraduates, whereas males significantly prevailed among the residents, with a six to one proportion. In contrast, the proportion of males and females was similar among postgraduates and professors, (Figure 2). This observation agrees with the literature, which shows that the number of women entering medicine in Brazil has been higher than the number of men since $2009^{2}$. Women are already a majority among professionals younger than 29 years and the estimate is that there will be an equilibrium between the number of men and women practicing medicine in the Country by 2028 . There is also evidence that females are a majority in specialties linked to basic health care such as internal medicine, pediatrics and gynecology and obstetrics, but not in surgery. A study has shown that only $22 \%$ of final year students were interested in surgery. This study also suggested that promoting the academic and scientific side of surgery, along with career opportunities available, may be an important avenue to encourage students into surgery ${ }^{3}$. 


\section{Proportion as sex percentage of the authors}

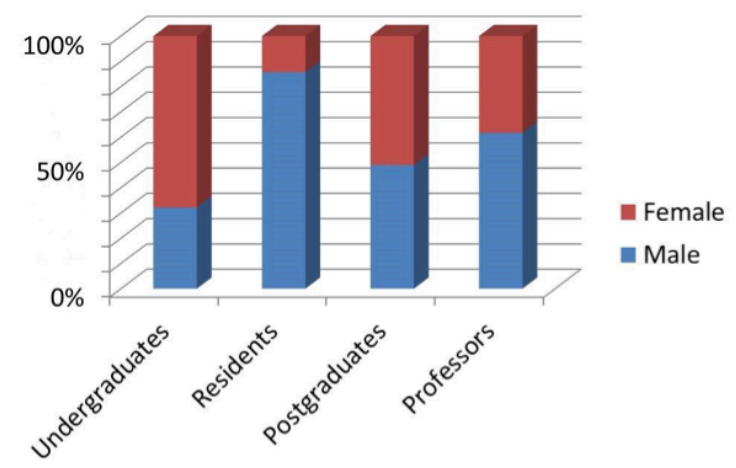

FIGURE 2 - Proportion as sex percentage of the authors participating in the articles published in this supplement trilogy.

As shown in the literature and also based on our own personal experience, over the years, undergraduates, especially women, have actively participated in both clinical and experimental and translational studies, but are choosing a specialty taking into consideration their lifestyle after graduating, and surgery is definitely not the best choice in terms of lifestyle. Gauvin ${ }^{4}$ reported a survey of medical students at the Mayo Clinic in which $63 \%$ of students identified the unfavorable lifestyle of surgeons and/or surgical residents as an important negative influence. Similarly, another author reported a survey of 120 fourth-year students at the Rush Medical School, in which lifestyle was identified as the most common reason for not selecting a career in surgery by $82 \%$ and $69 \%$ of male and female respondents, respectively ${ }^{5}$. On the other hand, a Canadian study has shown that women surgeons practicing in Canada are able to combine productive careers with rewarding family lives and are satisfied with their decision to do so despite the compromises involved. ${ }^{6}$ The engagement of medical students in a future career in surgery is clearly important to the community. It is a concern that many medical schools seem to be decreasing the exposure of students to both surgical science and surgeons ${ }^{7-9}$.
The XIV International SOBRADPEC Congress and Translational Research Forum, with its theoretical program and the exhibit of abstracts and full papers published in these supplements, coordinated by Dr. Saul Goldenberg, full professor of Escola Paulista de Medicina-UNIFESP and Editor of Acta Cirúrgica Brasileira, is an attractive proposal directed at showing to younger people the beauty of translational science and surgery in general, and to more experienced professionals the importance of teaching these specialties in medicine. This is definitely a way to attract in an increasing and effective manner young medical students, regardless of sex, to the fascinating specialty that is surgery.

\section{References}

1. Castro e Silva O, Silveira MRG. XIV International SOBRADPEC Congress and Translational Research Forum. A current approach. Acta Cirurgica Brasileira. Acta Cir Bras.;29 Supl 1:1-2.

2. Scheffer MC, Cassenote AJF. A feminização da medicina no Brasil. Rev Bioét. 2013;21:268-77.

3. Ek EW, Ek ET, Mackay SD. Undergraduate experience of surgical teaching and its influence on career choice ANZ J Surg. 2005;75:713-8.

4. Gauvin JM. How to promote medical student interest in surgery. Surgery. 2003;134:407-8.EDUCATION

5. Wendel TM, Godellas CV, Prinz RA. Are there gender differences in choosing a surgical career? Surgery. 2003;134:591-6.

6. Mizgala CL, Mackinnon SE, Walters BC, Ferris LE, McNeill IY, Knighton K. Women surgeons: results of the Canadian population study. Ann Surg. 1993;218:37-46.

7. Truskett P. Surgeons of the future: where will they come from? ANZ J Surg. 2014;84:399-400.

8. Woolf SH. The meaning of translational research and why it matters. JAMA. 2008;299:211-3.

9. Castro e Silva O. Surgery from experimental research to clinical application and vice-versa. Acta Cir Bras. 2006;21 Suppl 1:1-2. 